\title{
Control of malaria outbreak due to Plasmodium vivax in Aswan Governorate, Egypt
}

A. Kandeel, ${ }^{1}$ A.A. Haggag, ${ }^{7}$ M. Abo El Fetouh, ${ }^{1}$ M. Naiel, ${ }^{7}$ S.A. Refaey, ${ }^{7}$ A.H. Hassan ${ }^{2}$ and R.M.R. Ramzy ${ }^{3}$

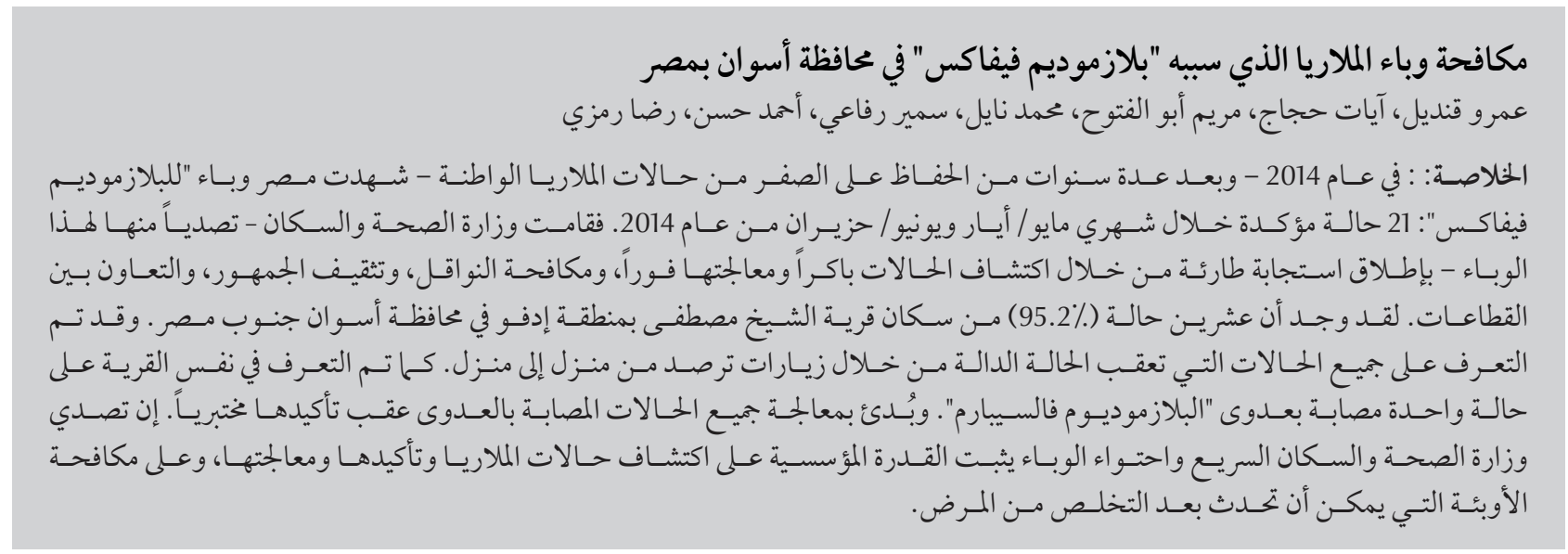

ABSTRACT In 2014, after several years of maintaining zero malaria indigenous cases, Egypt had an outbreak of Plasmodium vivax: 21 confirmed cases during May-June 2014. In response to the outbreak, the Ministry of Health and Population (MoHP) launched an emergency response through early detection and prompt treatment of cases, vector control, public education and intersectoral collaboration. Twenty cases (95.2\%) were residents of El-Sheikh Mostafa village, Edfu district, Aswan governorate, southern Egypt. All cases, consequent to the index case were identified through house-to-house surveillance visits. One $P$. falciparum-infected case was also identified in the same village. Treatment of all infected cases was initiated following laboratory confirmation. The MoHP's rapid response to and containment of the outbreak demonstrates the institutional capacity for detection and control of outbreaks which can occur after elimination.

\section{Lutte contre une flambée de paludisme à Plasmodium vivax dans le Gouvernorat d'Assouan (Égypte)}

Résumé En 2014, après s'être maintenue plusieurs années sans aucun cas autochtone de paludisme, l'Égypte a connu une flambée de Plasmodium vivax : 21 cas confirmés entre mai et juin 2014. En réponse à la flambée, le ministère égyptien de la Santé publique et de la Population a mis en place un plan d'urgence comprenant le dépistage précoce et le traitement rapide des cas, la lutte antivectorielle, la sensibilisation du public et la collaboration intersectorielle. Vingt de ces cas $(95,2 \%)$ se sont déclarés chez des résidents du village d'El-Sheikh Mostafa, dans la circonscription d'Edfou (Gouvernorat d'Assouan, au sud de l'Égypte). Suite au cas indicateur, la totalité des cas a été identifiée grâce aux visites de surveillance effectuées au porte-à-porte. Un cas d'infection à $P$. falciparum a également été identifié dans le même village. Après confirmation en laboratoire, le traitement de l'ensemble des cas infectés a été entrepris. La réponse rapide du ministère de la Santé publique et de la Population et l'endiguement de la flambée attestent de ses moyens institutionnels pour la détection, la confirmation et le traitement du paludisme, ainsi que la maîtrise des flambées susceptibles de survenir après l'élimination de la maladie. 


\section{Introduction}

Egypt has achieved a steady decline in malaria transmission over the past decades. In 1989, Egypt was listed among malaria-endemic countries with nationwide malaria control programs (1). The disease control efforts were shared between the Malaria Control Programme and the general health services based on primary health care. In 1999, the Roll Back Malaria initiative was launched in the Eastern Mediterranean Region (2). Egypt was among the countries that updated its national strategies for malaria control and elimination according to the objectives of the initiative. By 2001, malaria was firmly under control, therefore, the Ministry of Health and Population (MoHP) modified its goal to elimination of malaria transmission through a strong, time-limited attack on residual foci according to Roll Back Malaria established principles of malaria eradication. During 2010-2013, Egypt successfully eliminated malaria (maintained zero indigenous cases), but remained in the stage of prevention of re-introduction of malaria (3). In fact, the country has had reports of introduced cases or limited outbreaks of indigenous cases (4). One of the major challenges in controlling malaria is the re-introduction of the infection due to international travel and cross-border population movement from malariaendemic countries (5).

Re-introduction of malaria (or small outbreaks) has occurred in some Eastern Mediterranean Region countries that have been free of malaria. For instance, an imported case from Pakistan resulted in a small outbreak ( 30 cases of vivax malaria) in Jordan during 1990 (6). In 1998, due to Somali refugees, a small outbreak (21 cases of falciparum malaria) occurred in Oman which had been free of falciparum malaria (but not vivax) (6). Also, in Lebanon 2 small outbreaks of vivax malaria occurred during 1997-1998 (6). Malaria outbreaks represent a clear threat to maintaining the achievement of malaria elimination and enormous efforts should be directed towards controlling them.

This article describes an outbreak which resulted in 21 cases of Plasmodium vivax in Aswan governorate, Egypt between May and June 2014. In particular, it describes the intensive malaria control activities carried out by the MoHP central officials and local health authorities in the affected village and its surroundings, and the outcomes.

\section{Outbreak and response}

On 26 May 2014 the first confirmed malaria case in Aswan governorate was reported to the Preventive Sector, MoHP. The index case was a male (37 years of age) from El-Sheikh Mostafa village (24 57' 52.2144" N and 32 54' 55.53" E) in Edfu district, located approximately $120 \mathrm{~km}$ north of Aswan city. It had a population of approximately 4600 inhabitants. On 28 May, the MoHP mounted an emergency response which included early case identification, prompt treatment, vector control, public education and intersectoral collaboration for environmental manipulation. The overall coordination of the response was carried out by a mission from the Preventive Sector MoHP.

\section{Mobilization of surveillance teams for early case identification}

During May-June, 2014, 20 surveillance teams, each formed of 2 public health workers and 2 laboratory technicians, visited all houses in El-Sheikh Mostafa village and interviewed 3409 households. Data were collected on residents with fever or recent history of fever (in the previous 3 days) and their blood was screened for malaria. Teams were also charged to take a meticulous case history with a detailed travel history from all confirmed cases and elicit names of their contacts. The teams then searched for all the contacts, who had blood taken for malaria screening.

Subsequent screening involved examination of those were not present at the initial visit, and re-examination of persons with fever and their contacts, including household members, neighbours, friends and associates who were likely to have a similar exposure. This exercise involved two successive screenings of 2279 and 2669 people. Furthermore, 2116 randomly selected residents of six surrounding villages were interviewed and screened for malaria. The sample included 25 Sudanese who were temporarily visiting or residing in the study villages.

\section{Case confirmation}

Malaria cases were confirmed on laboratory diagnosis which was based on a rapid diagnostic test (RDT) and microscopy for confirmation by identification of the malaria species. The RDT (CareStart ${ }^{\text {mw }}$ Malaria HRP2/pLDH antigen test, produced by American Access Bio Company; batch number MV14D02, period of validity to March 2016) was used as a primary screening test. For each RDT-positive case or suspected case based on recent history of fever, thick and thin blood smears were prepared. Thick films were examined by two observers and the malaria species was confirmed by an additional experienced technician.

\section{Prompt treatment}

Malaria-confirmed cases were treated at the Edfu Fever Hospital. P. vivax infected cases were treated with Coartem $(20 \mathrm{mg}$ artemether and $120 \mathrm{mg}$ lumefantrine), twice a day with a meal for 3 days ( 6 doses). On the fourth day and onwards for 14 days, after the blood film became negative for malaria, Primaquine $(0.25 \mathrm{mg} / \mathrm{kg})$ single dose was administered. The P. falciparum infected case was treated similarly with Coartem.

Laboratory reassessments were made on days 1, 2 and 3 post Coartem treatment, before subjects were 
discharged from the hospital, and then weekly for the remainder of the followup period (i.e. on days 7, 14, 21 and 28). Patients were advised to return on any day during the follow-up period if symptoms returned and not to wait for the scheduled visit.

\section{Public education and community mobilization}

Several training sessions for local health workers were conducted to ensure that they carried out their tasks correctly. In addition, health workers were equipped with necessary information on malaria to deliver to communities during the field surveys. This included correct knowledge of causes (mosquito transmission) and symptoms of malaria (high fever most frequently with peaks every 2-3 days, generally with chills and strong headache), use of indoor residual spraying for vector control, and availability of free diagnosis and treatment services. Training sessions included health workers in the rural health centre of El-Sheikh Mostafa village as well as male and female health care providers recruited from 28 other rural health centres in Edfu district. Malaria posters in Arabic were posted at points of maximum visibility in the rural health centres and hospitals. Similarly, pamphlets, brochures, fliers and fact sheets in Arabic were distributed by health workers. To further raise the awareness in Edfu district communities, physicians and trained health care providers conducted several meetings with community leaders and other "influential" residents at all levels including local authorities, school teachers and religious leaders. Television interviews and short advertising programmes were broadcast to cover Aswan and other southern governorates through a local television station.

\section{Vector control}

The vector control plan included identification of the anopheles vector species, their distribution and densities as well as their breeding sites in Edfu district. Two additional geographically adjacent districts (Esna, Luxor governorate and Kom Ombo, Aswan governorate) were surveyed to determine the distribution of anopheles malaria vector mosquitoes. Anopheles sergentii has been recorded as a malaria vector in the southern part of the Nile Valley, Egypt (7). Detection of anopheles vector was followed by systematic application of different interventions in combination and in synergy with each other. Application of chemical methods for vector control, which included larviciding and adulticiding, indoor residual spraying and space spraying, conformed to WHO guidelines (8).

A total of seven sanitary teams were formed. Of these, four were assigned to work in Edfu district, two in Kom Ombo and one in Esna. A team was composed of a supervisor, six sanitary inspectors, five health workers and a malaria prevention worker. Entomological surveillance and vector control activities were implemented in affected areas as appropriate. To support vector control activities, an entomology laboratory was set up at the premises of the Edfu Central Hospital. The laboratory was equipped to support assessment of mosquito density, mosquito examination and identification of wild caught mosquitoes.

\section{Intersectoral collaboration for environmental management}

Environmental management as a means for eliminating or destroying mosquito breeding sites was carried out in collaboration with the Ministry of Agriculture and Ministry of Environment. Environmental management or manipulation to destroy breeding sites included increasing water flow in irrigation drainage canals by mechanical removal of weeds and other vegetation as well as making their shorelines steeper to reduce shallow spaces suitable for mosquito breeding. Several borrow-pits filled with ground water and bushes, creating mosquito breeding sites, were found in Edfu district. These are breeding sites where larvicide application is not effective. Therefore, in collaboration with the Ministry of Environment, the borrow-pits were filled with soil and covered with earth.

\section{Outcomes}

\section{Identification and treatment}

A total of 1436 houses were visited from 26 May to 14 June during the community surveillance, 12938 people were interviewed and 164 fever cases were identified and referred to Edfu Fever Hospital. Of these, 21 (12.8\%) cases of vivax malaria were confirmed on laboratory diagnosis (Figure 1). While 20 P. vivax infected cases were from El-Sheikh Mostafa village, 1 (male, 23 years of age) was from a surrounding village (Om Salama village). Figure 2 shows the distribution of malaria cases as plotted on an aerial imagery of El-Sheikh Mostafa village created by Google Earth program A P. falciparum infected case (a female of about 90 years of age) was coincidentally identified upon screening a randomly selected sample from villages surrounding El-Sheikh Mostafa village. She had no malaria signs or symptoms and was not able to confirm previous infection or treatment of malaria. All infected subjects were treated and discharged from the Edfu Fever Hospital. None of the cases had any complications and the last case had onset of symptoms on 14 June 2014 and was discharged on 1 July 2014. The ages ranged from 6 to 90 years and 11 were males (Table 1). All cases were discharged from the fever hospital after successive negative blood films in 4 consecutive days.

\section{Vector control}

Investigations of malaria vector in Edfu district included an area of 38 $\mathrm{km}^{2}$ and 16 villages. Adult and aquatic 


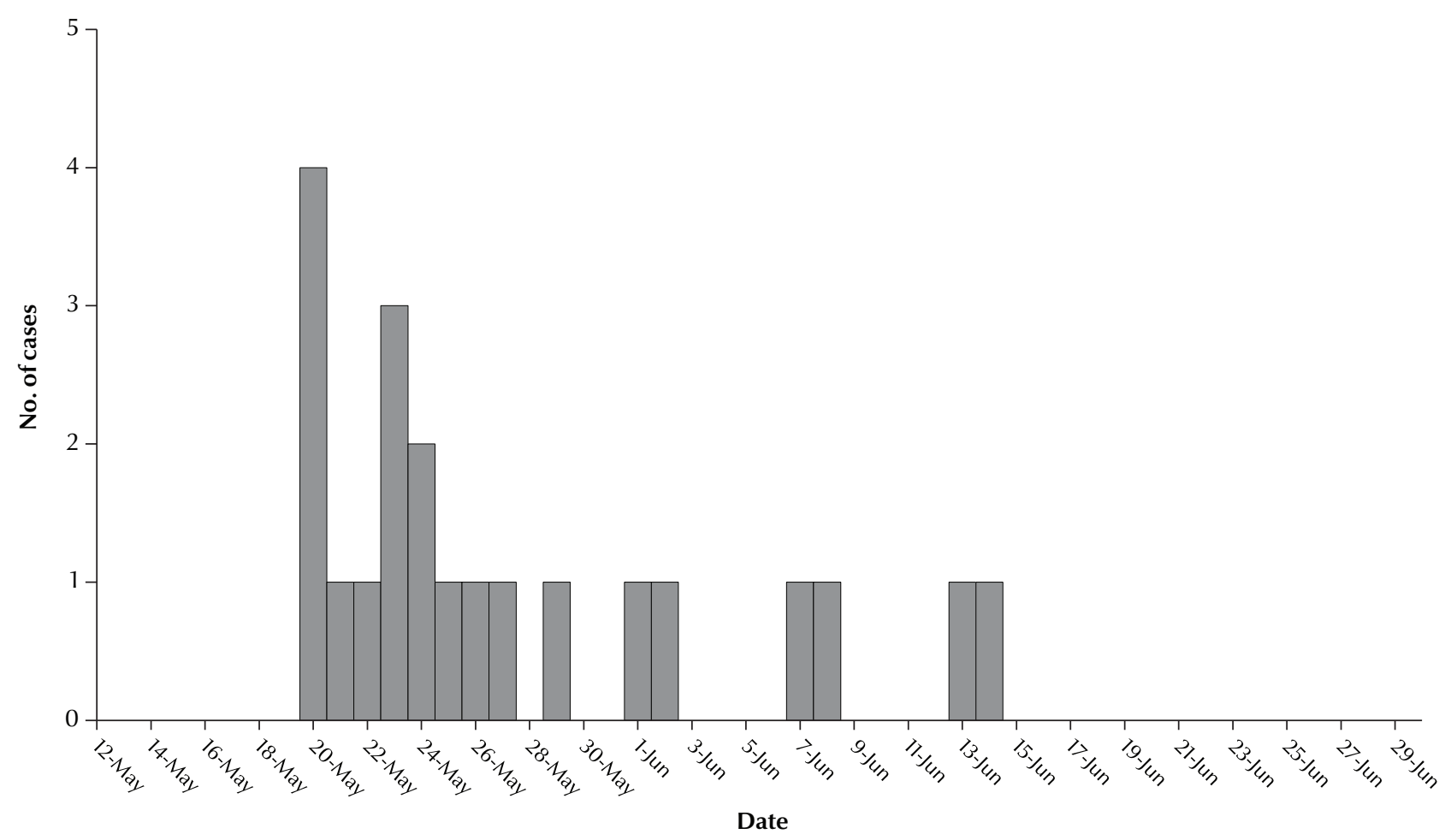

Figure 1 Confirmed cases of Plasmodium vivax malaria in Edfu, Aswan by date of onset, May-June 2014

stages of Anopheles spp. were collected in several localities. Of the fifteen grids in Edfu district, An. sergentii breeding sites were identified in 6, mostly in irrigation canals and drainage canals around affected communities. Out of 41 and 13 areas investigated in Kom Embo and Esna districts, respectively, one area $(2.4 \%)$ and three areas $(23.0 \%)$ were identified with An. sergentii breeding sites. On 1 June, before any corrective action was taken, about 100 mosquito larvae were collected per collection station in the breeding sites. Of these, about 20\% were identified as An. sergentii. Larvicidal treatment was applied to all water bodies where Anopheles spp. were identified and by 8 June 8 and onwards, no mosquito larvae could be detected.

A total of 27 irrigation drainage canals (each of about $6 \mathrm{~km}$ ) were cleaned to remove vegetation and improve water movement as a means to destroy breeding sites. This was followed by larvicidal treatment. Six borrow-pits [4 borrow-pits of about 5 feddans in area (approximately 2 hectares) and 2 of 2.5 feddans] filled with ground water and bushes sheltering An. sergentii aquatic stages were identified around El-Sheikh Mostafa village. To eliminate the breeding sites, about $90 \%$ of the borrow-pits were filled with soil and covered with earth.

An average of 70-75 adult Anopheles spp. was collected per day using the different collection methods, before the application of adulticiding measures. Of these, 20\% were identified as An. sergentii. Indoor residual insecticide spraying was used to control adult $A n$. sergentii. Two types of indoor residual insecticide spraying were applied in a total of 1436 houses in El-Sheikh Mostafa village. The walls of 4704 rooms were painted with indoor residual insecticide. In addition, space spraying was applied daily before sunset in all affected communities. Following such activities, very few adult anopheles mosquitoes were collected by 7 June and onwards.

\section{Discussion}

Reported data clearly demonstrate that the health system in Egypt was quick and effective in responding to the malaria outbreak during May-June 2014 in Aswan governorate. By the end of June, 2014, the last case was cured and discharged from the Edfu Fever Hospital. Since then (almost a two years now) no malaria case has been diagnosed, indicating success in controlling the outbreak. The early case identification strategy employed by the MoHP of screening contacts and other community members resulted in the identification of $28.6 \%$ of the malaria cases.

Several factors contributed significantly to the success in controlling the malaria outbreak. These included dissemination of information to medical and paramedical staff on malaria status in affected areas and enhancement of malaria awareness among the at-risk population. Access to free laboratory diagnosis and treatment was a key issue, 


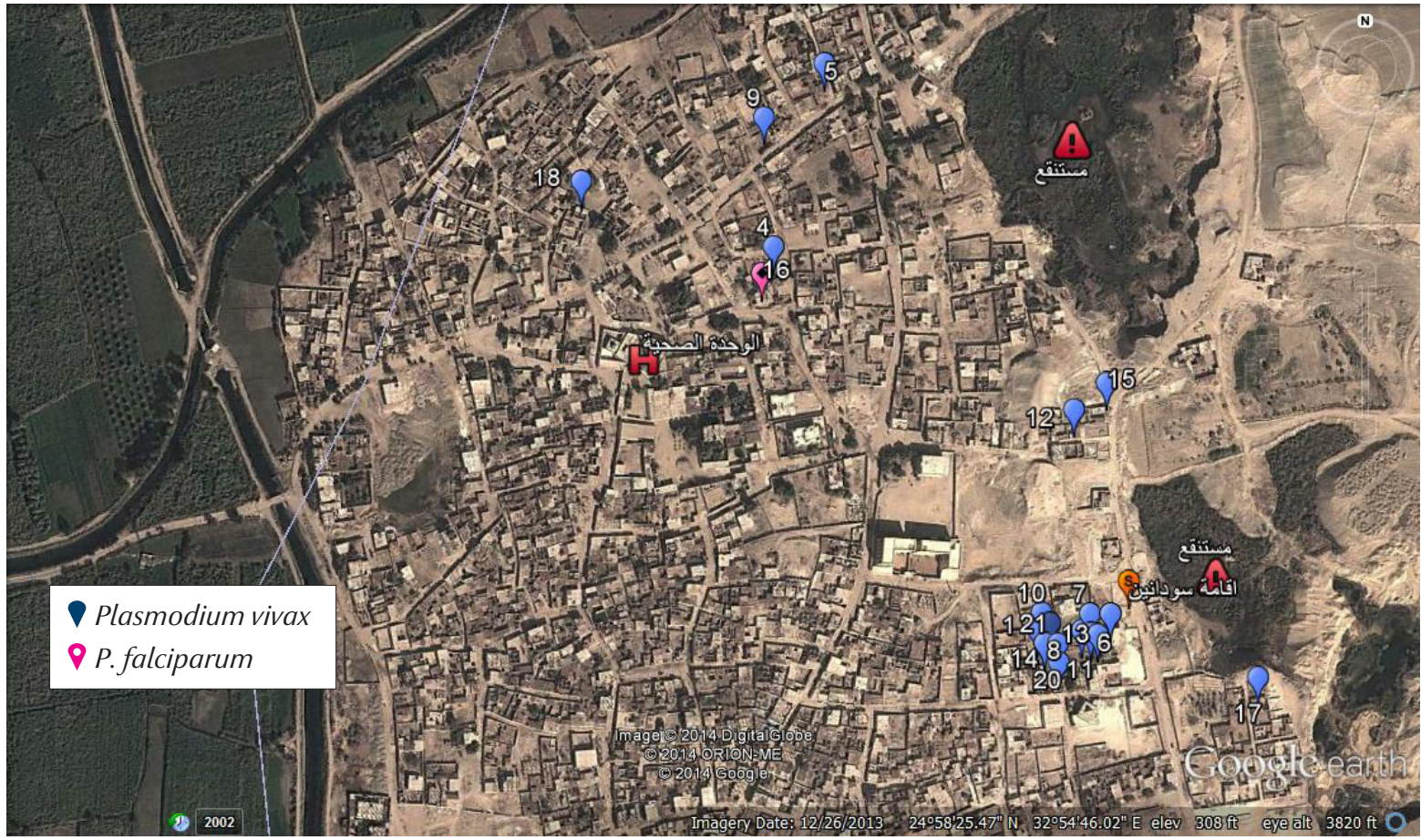

Health care facility

Borrow-pits filled with ground water

Figure 2 Aerial image of El-Sheikh Mostafa village showing the distribution of the malaria cases: created by Google Earth program

particularly for the affected communities who are already socioeconomically compromised. These were coupled with implementation of vector control measures aimed at effectively reducing aquatic stages and adult vector populations and hence malaria transmission. The implemented vector control measures avoided the repeated use of the same class of insecticides or insecticides with similar modes of action which could lead to the build-up of insecticide resistance. It is worth noting that extensive efforts by and tremendous resources from MoHP, Ministry of Agriculture and Ministry of Environment were required to control this malaria outbreak.

The coincidental detection of the $P$. falciparum case is of interest. An asymptomatic old lady residing in El Fawzah village (approximately $5 \mathrm{~km}$ southwest of El-Sheikh Mostafa village) was detected by RDT and confirmed by blood smear microscopy. Neither the duration of the infection nor the time of previous malaria treatment, if any, could be verified. Detection of asymptomatic carriers of $P$. falciparum parasites has been previously reported (9). Malaria infections have been detected in subjects after 8-9 years of leaving endemic areas (10,11). The time interval from last possible exposure to malaria and the

\begin{tabular}{lccc}
\hline \multicolumn{2}{l}{ Table 1 Age and gender distribution of malaria cases in Edfu district, Aswan governorate, } & \\
\hline Age group (years) & Males & Females & Total \\
& No. & No. & 4 \\
$\leq 10$ & 1 & 3 & 10 \\
$11-20$ & 7 & 3 & 3 \\
$21-30$ & 2 & 1 & 3 \\
$31-40$ & 1 & 2 & 1 \\
$41-50$ & - & 1 & 1 \\
$>50$ & - & 11 & 22 \\
Total & 11 & 11 & \\
\hline
\end{tabular}

aPlasmodium falciparum case. 
accidental diagnosis of the infection has been as long as 13 years (9). Such a finding highlights the need for improved high throughput and low-cost methods to detect these individuals, probably harbouring low parasite densities.

One piece of information lacking on the outbreak is that we have no solid explanation of how the outbreak started. It probably started through illegal crossborder movement of individuals between Aswan governorate and Sudan. However, none of the malaria infected individuals admitted recent travel to Sudan and all the Sudanese examined for malaria $(n=$ $25)$ were free of infection. Nonetheless, it is known that, locals cross the border illegally all the time for different reasons.
Some residents of Edfu villages have reported illegal Sudanese border crossing to teach locals gold mining. Such activity would result in the formation of more mosquito breeding places.

Egypt has achieved malaria elimination (maintained zero indigenous cases) for several years and succeeded in the containment of the last outbreak. However, this does not exclude the possibility of re-introduction of malaria to the country again. Therefore, there is a great need for strengthening collaboration with the national services in Sudan in order to deal with immigration and cross-border movement and suppress the illegal movement of people across the border.

\section{Acknowledgements}

We thank the field teams of the Vector Control Department, Malaria Control Department, Surveillance Unit, Communicable Diseases Department, MoHP, the Edfu Fever Hospital, Aswan, and the staff of the Research Institute of Medical Entomology for their technical assistance. Our thanks are extended to the Aswan Health Directorate, the Edfu Health District and the Gambia Control Department in Aswan for their logistical support when needed. All costs for containment of the malaria outbreak were met by the MoHP.

Competing interests: None declared.

\section{References}

1. Consultation on epidemiological malaria information at national and regional levels. Amman, Jordan, 25-30 November 1989 (http://applications.emro.who.int/docs/who_em_ mal_217_e_en.pdf, accessed 1 April 2016)

2. Report on the National Malaria Programme Managers' meeting on Roll Back Malaria (RBM). Damascus, Syrian Arab Republic, 1-3 April 2001 (http://applications.emro.who.int/ docs/who_em_mal_267_e_I_en_14389.pdf, accessed 1 April 2016).

3. Report on the tenth intercountry meeting of national malaria programme managers. Sharm El-Sheikh, Egypt 18-20 February 2013 (http://applications.emro.who.int/docs/IC_Meet_ Rep_2013_EN_14905.pdf?ua=1, accessed 1 April 2016).

4. Kenawy MA. Review of anopheles mosquitoes and malaria in ancient and modern Egypt. J Mosq Res. 2015;5(4):1-8.

5. Zucker JR. Changing patterns of autochthonous malaria transmission in the United States: a review of recent outbreaks. Emerg Infect Dis. 1996 Jan-Mar;2(1):37-43. PMID:8964058
6. Guidelines on prevention of the reintroduction of malaria. Cairo: WHO Regional Office for the Eastern Mediterranean; 2007 (EMRO Technical Publications Series, 34).

7. Cope SE, Gad AM, Presley SM. New record of the malaria vector Anopheles sergentii in the southern Nile Valley of Egypt. J Am Mosq Control Assoc. 1995 Mar;11(1):145-6. PMID:7616183

8. Pesticides and their application for the control of vectors and pests of public health importance. Sixth edition. Geneva: World Health Organization; 2006.

9. Ashley EA, White NJ. The duration of Plasmodium falciparum infections. Malar J. 2014 Dec 16;13:500. PMID: 25515943

10. Szmitko PE, Kohn ML, Simor AE. Plasmodium falciparum malaria occurring 8 years after leaving an endemic area. Diagn Microbiol Infect Dis. 2009 Jan;63(1):105-7. PMID:18945569

11. Theunissen C, Janssens P, Demulder A, Nouboussié D, VanEsbroeck M, Van-Gompel A, et al. Falciparum malaria in patient 9 years after leaving malaria-endemic area. Emerg Infect Dis. 2009 Jan;15(1):115-6. PMID:19116068 